\title{
Selection Advantage Pattern of International Sci-Tech Cooperation and Empirical Analysis
}

\section{Li Li, Bin Yu}

Shenzhen Graduate School, Harbin Institute of Technology, Shenzhen, China.

Email:ximlli@yahoo.com.cn, yu1985bin@gmail.com

Received November $15^{\text {th }}, 2010$; revised December $18^{\text {th }}, 2010$; accepted December $24^{\text {th }}, 2010$.

\begin{abstract}
Traditional international sci-tech cooperation theories mainly focus on the ability and advantage owned by cooperative parties, and according to which to guide the direction of international science and technology cooperation. Based on the integration of traditional theories of international science and technology cooperation and concrete practice, this paper proposes the selection advantage pattern and matching mechanism, which comprehensively take cooperator advantages, specification of project and change in circumstance into account and will play a guiding role in terms of determining the key country or region with which to prior carry out international science and technology cooperation. This paper also gives an analysis of the current status of industry development in Guangdong province and the research upon competitiveness evaluation of the world's related leading technology, puts forward corresponding countermeasures and suggestions on the science and technology cooperation patterns and approaches in terms of technological level and resources of Guangdong province.
\end{abstract}

Keywords: International Science and Technology Cooperation, Competitiveness Analysis, Selection Advantage Pattern

\section{Introduction}

International science and technology cooperation means the science and technology research or communication for the mutual aim, conducted by governments, firms, institutions and individuals in two or more countries or regions; or to realize the recombination of production factors and constant improvement of production condition through technology introducing, digesting, innovating and diffusing between nations, for the purpose of minimizing the profit of cooperating parties, adapting the coordinated development of science and technology and productivity, and promoting economic relations between nations [1]. Currently, international science and technology cooperation is carried out quickly and widely between countries and regions worldwide, which is the objective trend of global allocation and flow of scientific and technological resource elements, and reflects the fact that international science and technology cooperation is the common needs of the development of the country and region. However, the problems that how to excavate and know clearly the world leading technology and accurately judge the key country and region needing to strengthen international science and technology coopera- tion, so as to make the mode and policy capable of effectively promoting international science and technology cooperation, still need further study. With globalization trends of economic and technological cooperation, correct understanding of the basic approach of international science and technology cooperation and of the regularity of regional science and technology cooperation, along with the realization of optimizing the allocation of resources, adapting coordinated development of science and technology and productivity, and promoting economic relations between countries, we are able to rapidly raise the science and technology development level of certain country or region, and strengthen core competitiveness and facilitate economic growth as well.

\section{Literature Review and Research Questions}

Exposed to globalization, knowledge economization and rapid development of science and technology, people are increasingly convinced of the enormous impact of international science and technology cooperation on effectively optimizing the allocation of global scientific and technological resources, improving the competitiveness of country or region and enhancing economic growth. In 
theory circle, researchers worldwide have attached importance to and conducted extensive study on the cosmopolitan subject of international science and technology cooperation. The topics conducted abroad included: the basic theories of international science and technology cooperation, such as theory of interdependency, theory of balanced growth, growth pole theory, factor endowment theory, comparative advantage theory, technology transfer theory, grad process theory, theory of monopoly advantage and so on; statistical analysis and empirical research of international science and technology cooperation status [2,3]; studies on form and policy of international science and technology cooperation [4]; impacts of international science and technology cooperation on academic institutions' performance [5]; R \& D and technology cooperation among international enterprises [6]; the cooperative environment problem during the process of international science and technology cooperation $[7,8]$.

Meanwhile, researches on international science and technology cooperation conducted at home mainly centered on the following themes that: international science and technology cooperation model studied by Wei Dazhi [9]; the international science and technology policy, which was researched by Li Xiaobing [10]; the relationship between the international science and the intellectual property studied by Gu Zuxue [11]; international science and technology cooperation and technology innovation, which was studied by several researchers, such as $\mathrm{Yi}$ Tong [12]; and international science and technology performance evaluation researched by Zhang $\mathrm{Ju}$ and $\mathrm{Wu}$ Danqing [13]. And the mechanism and organizational innovation, system construction and policy design had been made based on those researches above.

In spite of the remarkable achievement obtained in theory and practice area, and the deep study carried out in single subjects, with respect to resources, environment, investment, R \& D, technology transfer and intellectual property protection and so on, the researches on the comprehensive analysis and systematic study on outward regional science and technology cooperation showed obviously insufficiency. The problems that how to selectively carry out high-level science and technology cooperation with world key counties and regions, according to the principle of complementary advantages, how to build an effective platform for the international scientific and technological communication, the cooperation development and market development in high and new technology field, and how to establish a new cooperation model and cooperation mechanism capable of effectively promoting the international science and technology cooperation, become the urgent subjects to be studied.

\section{Research Method}

\subsection{Basis Assumptions}

First, the research objects concerned in this paper are all rational. Here, rationality has another meaning, aside from purchasing maximum self-interest, that one may restrict the interest of counterpart with potential threat at the cost of its own interest. For instance, advanced country may blockade techniques against its counterpart with potential threat and adopt export control policy and so on.

Second, the correct matching analysis and comprehensive evaluation towards cooperative parties are the foundation for actually operating international science and technology cooperation. The ability or advantage of cooperative parties' is only a prerequisite for cooperation, rather than a sufficient condition. Traditional theories just conducted theoretical analysis on the cooperative parties' resources, in terms of natural resource, human resource, technological condition etc, respectively, from which the conclusions drawn may prove inoperative or risky.

Third, the priority fields of a country or region act as the principal direction and major basis for international science and technology cooperation. The resource advantage and technological gap should be associated with the requirements of specific project, and meanwhile, the occurrence of international science and technology cooperation depends on that whether the advantageous resource matches the requirement of specific project.

Fourth, international science and technology cooperation circumstance today is under a dynamic state, in terms of world political circumstance, economic policy, technological and cultural environment etc. So international science and technology cooperation should take adjustment to changes in circumstance and select advantages constantly to ensure the effectiveness of carrying out international science and technology cooperation.

\subsection{Selection Advantage Pattern}

International science and technology cooperation should take factors from the following four aspects into account:

\subsubsection{Analysis on the Seeker's Development Fields with Priority and Advantage}

According to the overall layout of development plan, in term of national economy, technology and society in certain country or region, the seeker which represents the country or region looking for cooperation, needs to have an objective grasp of the development status of its leading industry and development fields with priority, to determine the advantageous direction with respect to resource, capital, technology, supporting facilities and pol- 
icy support, and then take the conclusion drawn above as the major basis and main direction for it carrying out international science and technology cooperation.

\subsubsection{Advantage Analysis of World Leading Technology Fields}

By means of a mass of literature search, data analysis and case studies, to judge and understand the core technologies in the development fields with priority of the seeker, and the countries and regions with leading technological advantage worldwide; and then to have a comprehensive analysis of the tendency of science and technology cooperation between the seeker and the country or region with leading technology concerned, the scientific and technological resource, management ability they own and the encouragement or regulation policy of government; and through the study on the technological gap of the party seeking cooperation in those associated fields, to finally determine the technical capacity and potential cooperative direction in those concerned fields which are most in need of development.

\subsubsection{Analysis of Circumstance for International Science and Technology Cooperation}

With the globalization of economic and technological activities, in order to avoid government regulation, system obstacle and blockade on techniques, at the same time to promote the successful launching of international science and technology cooperation, it is essential to correctly grasp the global allocation and optimal recombination direction of technical elements, to see clearly the evolutionary trend of current international science and technology cooperation, progress in international bi-lateral or multi-lateral mechanism and inter-countries science and technology cooperation fields propelled and advocated with emphasis by international organization.

\subsubsection{Judgment on International Science and Technology Cooperation Threshold}

Resource advantage and wide technology gap only can’t guarantee certainly the successful launching of international science and technology cooperation. In addition, the willingness, financing capacity, institutional factor, government policy, cooperative targets of cooperative parties, along with the requirements of specific project, in terms of technology concerned, supporting facilities and technical staff, and many other factors together contribute to the operability of cooperation.

The general idea of the model can be explained in details as follows: at first, we should determine the development fields with priority and understand the prior direction supported by government policy through the environmental analysis in terms of social, economy and technology of the seeker, namely, the party seeking for cooperation; then taking into account the technology gap, to ascertain the priority technology fields in each industry field with priority and find out the key countries and regions owning the advanced technical advantage in each related fields; and then according to the findings derived from previous steps, we have a comprehensive analysis on the technical cooperation trend, the scientific and technological resource, the management ability, as well as the encouragement or regulation policy of the government, in addition, to pay sufficient attention to changes in international scientific and technological cooperation circumstance and evolutionary tendency of the international scientific and technological cooperation, along with cooperative threshold and operability of specific project. We take the thoughts and steps described above as the important basis for the seeker to follow in seeking selection advantage and matching during international science and technology cooperation.

\subsection{Implementation Mechanism}

Figure 1 shows the selection advantage and matching mechanism of the international science and technology cooperation. We carried out the study through four dimensions. The first one is the development status analysis of development fields prioritized in certain country or region. And we will rank those industries, according to their average growth rate in recent years and share in GDP, for the aim of optimizing resource allocation, determining the industries with priority support and policy orientation; the second dimension is that: from the prospective of complementation, amongst the industry fields concerned to ascertain the priority technology fields to carry out international science and technology cooperation, and then from each of those technology fields with priority to judge and understand the seeker's core technology and the countries or regions possessing leading technical advantage concerned. The third one is that: in the light of the practice and law of development of international science and technology cooperation and by virtue of investigations on principal facilitating factor and mainstream pattern in different period to sum up dominant paradigms of international science and technology cooperation of different stages, and hold the evolutionary trend of current international science and technology cooperation. And the last dimension means through custom yearbook, to investigate import target of each leading technical product, and the calculated share in weighted average for each product, to some extent reflects the advanced status of various country in the fields concerned and the availability of technology or product. 


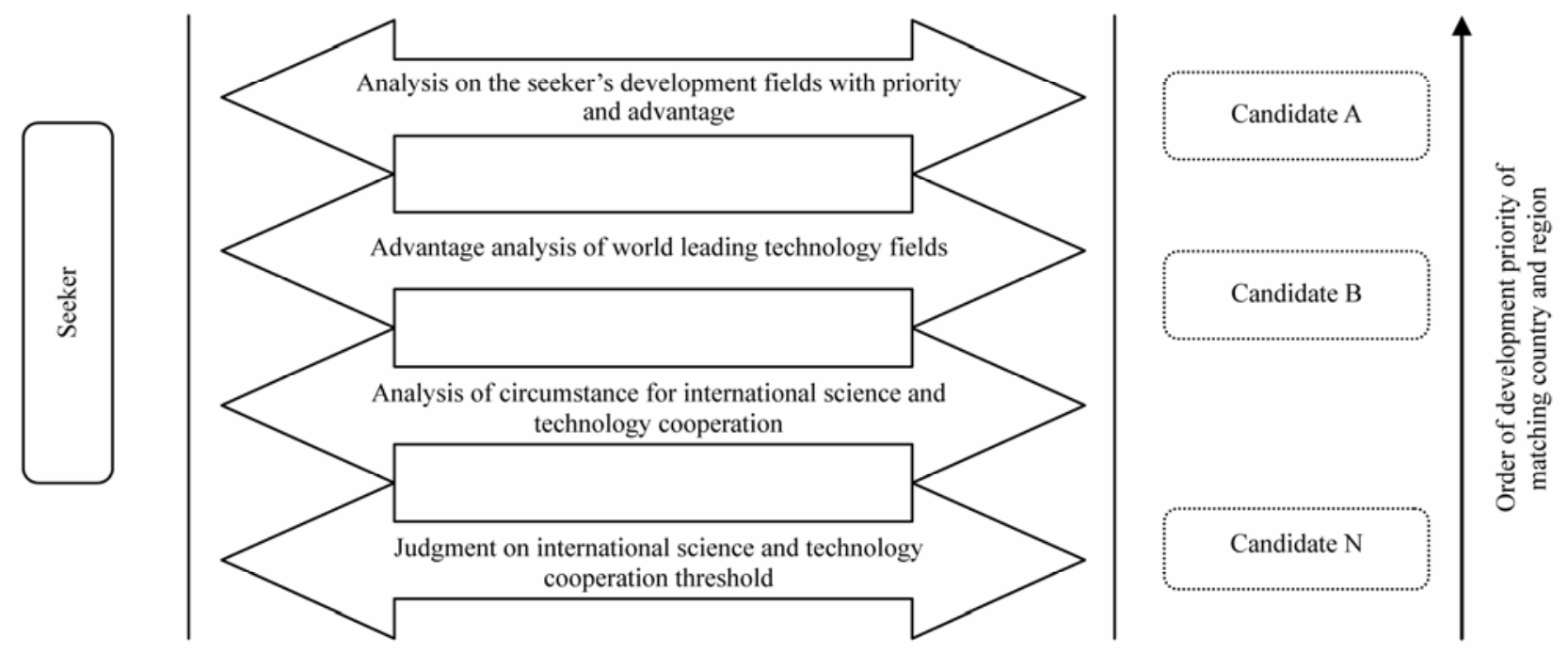

Figure 1. International science and technology cooperation selection advantage and matching mechanism.

\section{Empirical Analysis}

Since China's reform and opening-up in the 80s, Guangdong province has carried out extensive and various forms of international science and technology cooperation with many countries or regions. Multi-faceted international science and technology cooperation, the introduction and exchange of high-tech are becoming a key component of supporting the export-oriented economy of Guangdong Province to continue rapid development. Despite of lots of achievements in international science and technology cooperation, Guangdong province is still in an imbalance situation in terms of international science and technology cooperation with eastern and western countries, because of the geographic and historic reasons, the lack of adequate judgments on the priority countries and regions in the world it needs to strengthen cooperation with, and the weakness on the basic ways of international science and technology cooperation and systematic understanding of regional science and technology cooperation.

General idea: According to the overall layout and priority development areas of plans for the development of Guangdong's national economy, science and technology, and society, clear the leading industries needing to be prioritized. We analyze it from two directions, first is the development status analysis of eight leading industries in Guangdong province, by which sort these areas, in order to optimize resources allocation, and determine the industries with priority support and policy orientation; the second is taking into account both the eight leading industries in Guangdong province and the technology gap with international advanced level, from the complemen- tary perspective, determine the priority technology areas needing cooperation in each area, in which determine the leading technology products, then with the combination of the customs import and export targets, ascertain the priority in different countries or regions of each area. According to the two directions, define the countries or regions, with which Guangdong province to prioritize international cooperation.

Table 1 reflects the industrial added value of eight major industries in Guangdong Province in the recent four years (according to the new division regulation of statistical indicators division, data selection from 2005); Table 2 shows the average growth rate and average share of GDP, in the recent four years, of the eight leading industries in Guangdong province. The weighted value of these two variables above can determine the development status and key support direction of eight industrial in Guangdong province.

As for the second direction, in each field prioritized in Guangdong, we choose two representative leading-edge technology products, with the time span of two years, and examine their imports targets through the Customs Statistical Yearbook. The weighted average index share indicates, in some extent, the availability of the advanced technology or product of the world in the field. Figure 2 points out the key countries and regions with the corresponding leading-edge technology and products in eight major industries of Guangdong province. It shows both the advanced technology level of the world in the areas prioritized and the technology availability.

Taking into account both the eight major industries in Guangdong province and technology gap with international advanced level, from the complementary perspec- 
Table 1. Industry added value as a share of GDP in Guangdong province.

\begin{tabular}{|c|c|c|c|c|c|c|c|c|}
\hline \multirow{2}{*}{ Industry } & \multicolumn{2}{|c|}{2005} & \multicolumn{2}{|c|}{2006} & \multicolumn{2}{|c|}{2007} & \multicolumn{2}{|c|}{2008} \\
\hline & Added value & Share & Added value & Share & Added value & Share & Added value & Share \\
\hline Advanced manufacturing & 1896.82 & 0.085 & 2289.86 & 0.088 & 2602.57 & 0.084 & 3108.13 & 0.087 \\
\hline New material & 1689.24 & 0.076 & 2131.14 & 0.081 & 2802.53 & 0.09 & 3445.32 & 0.097 \\
\hline New energy & 1875.9 & 0.084 & 2380.6 & 0.091 & 2783.64 & 0.09 & 3303 & 0.093 \\
\hline Biology, medicine and health & 131.67 & 0.006 & 161.28 & 0.006 & 185.79 & 0.006 & 230.77 & 0.006 \\
\hline Modern services & 5919.48 & 0.265 & 6868.4 & 0.263 & 8503.1 & 0.274 & 9806.84 & 0.275 \\
\hline Oceanic resource and environment & 546.24 & 0.024 & 603.26 & 0.023 & 705.79 & 0.023 & 882.4 & 0.025 \\
\hline
\end{tabular}

Source: Guangdong Statistic Yearbook; China High-tech Industries Statistic Yearbook; Database of Zhonghong Industry.

Table 2. Leading industry development status in Guangdong province.

\begin{tabular}{|c|c|c|c|}
\hline & Average growth rate & Average share & Development status \\
\hline Information and Communication & 0.149 & 0.027 & 0.1 \\
\hline Advanced manufacturing & 0.179 & 0.086 & 0.142 \\
\hline New material & 0.268 & 0.086 & 0.195 \\
\hline new energy & 0.208 & 0.09 & 0.161 \\
\hline Biology, medicine and health & 0.206 & 0.006 & 0.126 \\
\hline Modern services & 0.183 & 0.269 & 0.217 \\
\hline Oceanic resource and environment & 0.173 & 0.024 & 0.113 \\
\hline Modern agriculture & 0.140 & 0.073 & 0.113 \\
\hline
\end{tabular}

Note: development status $=0.6 *$ average growth rate $+0.4 *$ average share.

tive, we determined the priority technology areas needing cooperation in each area. And according to the leading technology product index, we ascertained the countries, with which Guangdong province should prioritize science and technology cooperation, are: USA, Japan, France, Korea, Germany, England, Holland, Italy, Switzerland, Sweden, Singapore, Malaysia and so on; In the light of the sorts over the development speed and contribution of the eight areas of Guangdong province, modern services, new material, new energy and energy saving, advanced manufacturing should obtain the priority support of the external science and technology cooperation provided by the government.

This paper reveals that, in the modern service industry, Guangdong province should cooperate primarily with France, USA, England, Holland and Italy, focusing on Intelligent Transportation Systems, Web-based Education, Electronic Commerce, Modern Logistics and Digital Medical Technology; and it should cooperate with
Korea, Japan, USA, Germany, Malaysia, Thailand in new material industry, in terms of nano-material, high molecular material, metallic material, alloy material, atomic and molecular design of materials; as for new energy industry, it should cooperate with Japan, USA, Korea, Germany, France, focusing on nuclear technology, new energy power generation technology, technology of energy saving and reproducible energy technology; while in advanced manufacturing industry, the seeking for cooperation with Japan, Korea, USA, Germany, Malaysia and Thailand is necessary, including key technology and equipment of electronic manufacturing, automobile electronic technology, key process and equipment technology of machinery manufacturing, high-end home appliances, etc.

With the international science and technology cooperation's gradually increasing, the forms of science and technology cooperation are prone to diversification. Generally speaking, at this stage, for the countries Guang- 


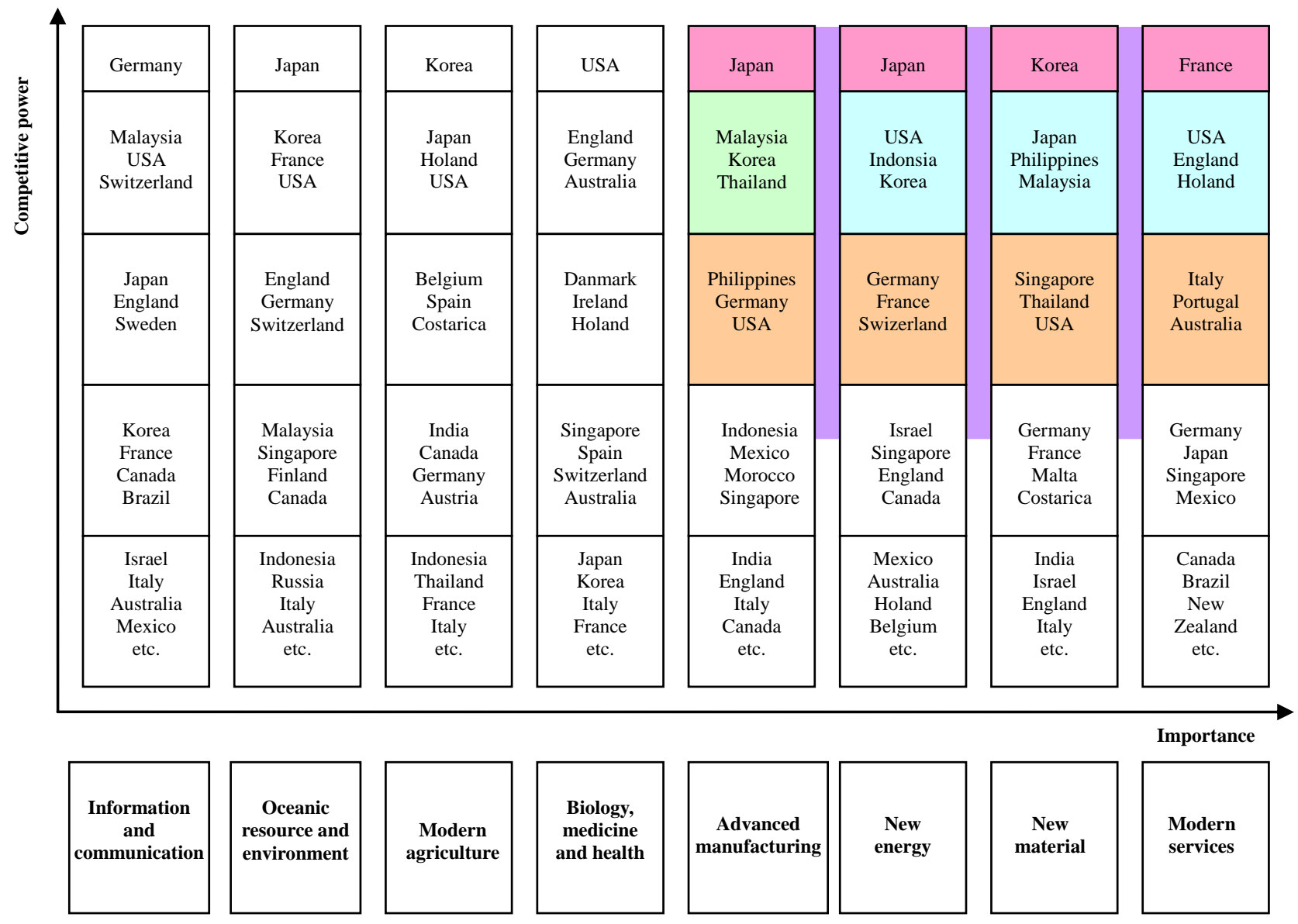

Figure 2. Correspondence relationship between eight industries and key cooperation countries.

dong will primarily cooperate with in information and communication, new material, new energy, biology, medicine and health, oceanic resource and environment, advanced manufacturing fields, the preferential patterns adapted are: Science and Technology Exhibition, Science and Technology Park, Technology Investigation, Technology Trade, Capital-Driven Pattern, Team Introduction, Multinational Alliances, Joint Laboratory, Cooperative Research, Joint Institution, etc. Guangdong should strongly promote the exchanges, introduction and cooperative research of high technology.

As to the countries with priority cooperation in modern service, modern agriculture industries, the cooperation patterns are International Funding, Complementary Resources, High-level Visits and Exchanges, CapitalDriven Pattern, Technology Trade, Exchange and Cooperation of Expert, Technology Information Exchange, Sharing of Network Information Resources, Technology Investigation, etc.

\section{Conclusions and Suggestions}

Carrying out the comprehensive analysis and systematic research of external regional science and technology cooperation is the basis and prerequisite to guarantee the success of international science and technology cooperation. By means of the comprehensive survey of both the advantages of cooperative parties, threshold of cooperation and cooperative circumstance, from the prospective of complementary, selectively carrying out high-level science and technology cooperation with main country or region, can realize the optimization allocation of scientific and technological resource, rapidly raise science and technology development level of certain country or region.

This paper proposed the international science and technology cooperation selection advantage pattern and matching mechanism, and pointed out the direction for the development fields with priority to carry out external science and technology cooperation, crucial factors and implementation method, which have guiding significance in determining the major country and region with which to preferentially carry out international science and technology cooperation, and in making the model and policy which are able to effectively propel international 
science and technology cooperation.

Based on the study of this paper, when carrying out international science and technology cooperation practically, we recommend that: 1) Understanding the development demand of certain country or region. Determine the direction of international science and technology cooperation according to the object of planning of certain country or region. For instance, a country may firstly determine its leading industry, and then carry out international science and technology cooperation centering on the leading industries. 2) Determining the content of prior cooperation. We are required of abundant effort to the assessment of the leading technology fields worldwide, then comprehensively analyze their technical advantage, cooperative tendency, science and technology resource, management ability and encouragement and regulation policy of government, and finally identify the direction and content of cooperation in most need of cooperation in concerned fields. 3) Selecting cooperator objectively. When selecting cooperator, we should consider such countries that can both make up for our deficiencies in leading industry and play a leading role in concerned fields. Through analysis of these four dimensions of international science and technology cooperation, to determine the priority order of the countries or regions we are going to carry out international science and technology cooperate with. 4) Conducting real-time monitoring on the whole process of science and technology cooperation. International science and technology cooperation should adjust rapidly according to the changes in circumstance, and select advantage constantly, so as to decrease the uncertainty existing in cooperation, and to avoid and defend risk.

The study conducted by this paper is more appropriate to the science and technology cooperation carried out between developing country and advanced country under disequilibrium condition. More case studies and discussion are expected to further perfect the model.

\section{Acknowledgements}

Research works in this paper are financially supported by the Soft Science Foundation of Guangdong Province (No. 2008B070800080).

\section{REFERENCES}

[1] X. L. Li, "Research on International Science and Technology Cooperation Mode and Strategy,” Ph.D. Thesis,
Jiangsu University, Zhenjiang, 2008, pp. 9-21.

[2] E. N. Comelia, "Ten Years of International Scientific Cooperation in Fisheries, Aquaculture and Coastal Zones: Some Preliminary Lessons,” Environment, Development and Sustainability, Vol. 10, No. 5, 2008, pp. 605-622. doi:10.1007/s10668-008-9153-4

[3] R. Ponds, "The Limits to Internationalization of Scientific Research Collaboration,” Journal of Technology Transfer, Vol. 34, No. 1, 2009, pp. 76-94. doi:10.1007/s10961-008-9083-1

[4] H. Y. Hou, H. Kretschmer and Z. Y. Liu, "The Structure of Scientific Collaboration Networks in Scientometrics," Scientometrics, Vol. 75, No. 2, 2008, pp. 89-202. doi:10.1007/s11192-007-1771-3

[5] A. Basu and R. Aggarwal, "International Collaboration in Science in India and Its Impact on Institutional Performance,” Scientometrics, Vol. 52, No. 3, 2001, pp. 379-394. doi:10.1023/A:1014239731175

[6] U. Cantner and A. Meder, "Technological Proximity and the Choice of Cooperation Partner," Journal of Ecnomic Interaction and Coordination, Vol. 2, No. 1, 2007, pp. 45-65. doi:10.1007/s11403-007-0018-y

[7] S. J. Christian and T. Jarle, "Globalisation or Europeanisation?” International Contact among University Staff, Vol. 49, No. 4, 2005, pp. 449-466.

[8] S. A. Kiswany, "Matei Ripeanu, Adriana Iamnitchi, Sudharshan Vazhkudai. Beyond Music Sharing: An Evaluation of Peer-to-Peer Data Dissemination Techniques in Large Scientific Collaborations," Journal of Grid Computing, Vol. 7, 2009, pp. 91-114.

[9] D. Z. Wei, “A Market Leading Mode of the International Science and Technology Cooperation in Shenzhen," Forum on Science and Technology in China, Vol. 1, 2005, pp. 140-145.

[10] X. B. Li, "Current Situation and Policies of International Science and Technology Cooperation in Chinese Enterprises," Technological Development of Enterprise, Vol. 24, No. 6, 2005, pp. 59-60.

[11] Z. X. Gu and Q. D. Zhao, “On Tortuous Lawsuit of Intellectual Property Rights in International Cooperation of Science and Technology," Journal of Central South University (Social Science Edition), Vol. 14, No. 4, 2008, pp. 499-506.

[12] Y. Tong, “Technology Transfer in Chinese International Science and Technology Cooperation," Forum on Science and Technology in China, Vol. 7, No. 4, 2007, pp. 38-43.

[13] J. Zhang and D. Q. Wu, “The Status, Efficiency and Tendency of International Science and Technology Cooperation between Research University and Government," Scientific Management Research. Vol. 21, No. 4, 2003, pp. 80-84. 